\title{
Pyrotechnic heater setup as a calorimeter: Micro- vs. nano- $\mathrm{Mg} / \mathrm{Fe}_{2} \mathrm{O}_{3}$ thermites
}

\author{
Konstantin Monogarov ${ }^{1}$, Nikita Muravyev ${ }^{1, *}$, Dmitry Meerov ${ }^{1}$, Denis Dilhan $^{2}$, and Alla Pivkina ${ }^{1}$ \\ ${ }^{1}$ Energetic Materials Laboratory, Semenov Institute of Chemical Physics, 119991, 4 Kosygin st, Moscow, Russia \\ ${ }^{2}$ Centre National d'Études Spatiales (CNES) 31401, 18 Avenue Edouard Belin, Toulouse, France
}

\begin{abstract}
Combustion of thermite composition $\mathrm{Mg} / \mathrm{Fe}_{2} \mathrm{O}_{3}$ with micron- and nano-sized components was studied in pyrotechnic heater setup. Pressed charges were burned out in hermetic steel tubes with simultaneous pressure and temperature registration. Advanced system of thermocouples connections allows drawing thermal maps of the steel case heating with high spatial and temporal resolution. Mathematical processing of raw thermal data gives the temperatures for thermite combustion. Initial temperature and setup orientation (either vertical or horizontal) show almost no influence on combustion temperature. Nanothermite produces in $500 \mathrm{~K}$ lower temperatures compared to micron-sized composition, apparently due to lower metal content in nano-Mg. Comparison of the experimental data with thermodynamic calculation output shows important differences in the combustion temperature and composition of products. Adiabatic temperature predicted is slightly lower than experimental and this fact is linked with formation of spinel $\mathrm{MgFe}_{2} \mathrm{O}_{4}$ phase, not accounted in computations. Thus, utilization of the pyrotechnic heater setup gives valuable information not only about pressure and porosity effects, but also about combustion temperature, composition of products and process mechanism.
\end{abstract}

\section{Introduction}

Thermites are energetic materials where the high heat release is produced by the reaction of metal with the metal oxide [1,2]. Recently, nanothermites, i.e., thermites with at least one of components at nanoscale, became a hot topic in pyrotechnic community. Its higher intimacy of mixing and enhanced kinetics of the reaction results in great burning rate values and short ignition times [3-6].

Emerging interest to thermite systems is driven by their properties: high enthalpy density (much greater than for electric batteries), high thermal and chemical stability, low sensitivity to mechanical stimuli, and capability to function in various gas environments $[1,7]$. Among the diverse applications proposed, there are some that use heat generated for welding and as a heat source $[8,9]$, gas formation for thrusters in space $[10,11]$, and specific products of the reaction as biocides $[12,13]$. Our group reported the elaboration of the pyrotechnic heater where several thermite compositions have been selected as a working body for device based on a certain criteria, like pressure of gases, rate of temperature rise and availability of starting components [14,15]. Typical use of pyroheaters is a fast heating-up of target materials, e.g., electrolytes in electric circuit in space satellite antennas [16]. Another, most recent, utilization of thermite reaction proposed by our team is a disruption of the end-of-use satellite parts or detachable rocket elements $[17,18]$. Here the aerodynamic heating ignites the reactive material, which, in turn, heats either the composite carbon material or titanium alloy up to its degradation or melting, respectively. This approach has a high potential in decreasing the cost and environmental hazards associated with launches.

Combustion of thermites has been studied for quite a long time, but till now there is no general theory and complete understanding, even for the common aluminum-iron oxide system. The main reason of this indeterminacy is the great influence of the experimental conditions: researchers study thermite combustion in hermetic tubes [19,20], ampoules [21], or open channels [22]. Along with the measurement conditions, the important factor is the powder properties (particle size, surface state, chemical activity). Density of the mixture is extremely important: its influence on burning rate is not linear and differs for micro- and nanothermites $\mathrm{Al} / \mathrm{MoO}_{3}$ [23]. These factors significantly affect the observed reactions, thus blurring the combustion mechanism.

Understanding this lack of information concerning thermite reaction, and based on our experience in fabrication of pyrotechnic heater, we came up with an idea to look at this setup as a source of information about temperature and pressure developments. During operation of pyroheater, i.e., combustion in hermetic tube, the pressure is rising due to evaporation, decomposition of the reaction products, and thermal expansion of formed gases. These pressure profiles were analyzed and the shift between convection and

Corresponding author: n.v.muravyev@ya.ru 
conduction-driven regimes have been shown at certain porosity level for micro- and nanothermite $\mathrm{Mg} / \mathrm{Fe}_{2} \mathrm{O}_{3}$ [24]. Present study examines the temperature profiles for both types of this thermite and compares the experimental findings with thermodynamic calculations. The new data for magnesium-iron oxide system clearly shows the potential of this approach for analysis of combustion reactions.

\section{Experimental}

\subsection{Materials}

Magnesium-iron oxide thermite composition was studied focusing on the particle size variation. Detailed characterization of the powdered components have been reported previously [14,15]. Micro-sized Mg powder (Russian tradename MPF-4) appears as shavings with an average size around 50 microns (via laser granulometry, Analysette 22 MicroTec Plus by Fritsch). Submicron magnesium (laboratory sample) represents spheres near $300 \mathrm{~nm}$ in diameter. Micro-sized iron oxide $\left(\mathrm{Fe}_{2} \mathrm{O}_{3}\right.$, according to Russian standard TU 6-09-1418-78) has a high specific surface area of $16 \mathrm{~m}^{2} / \mathrm{g}$ (via Micromeritics FlowSorb III 2305) due to considerable internal porosity within $\sim 15$-micron particles. Nano-sized $\mathrm{Fe}_{2} \mathrm{O}_{3}$ (laboratory sample) represents spherical particles with diameters within 0.05-0.3 $\mu \mathrm{m}$ (via scanning electron microscope Phenom by FEI).

Stoichiometric mixtures $\left(31 \% \mathrm{Mg}+69 \% \mathrm{Fe}_{2} \mathrm{O}_{3}\right)$ were prepared by addition of two powders in vial with hexane and ultrasonic processing for 15 minutes. Obtained pastes were dried at $313 \mathrm{~K}$ overnight, then pressed in steel tubes batchwise (internal diameter of 8 $\mathrm{mm}$, outer diameter of $14 \mathrm{~mm}$, and total length of 120 $\mathrm{mm}$ ). Pressure during the pressing was kept $300 \mathrm{MPa}$ for $3 \mathrm{~min}$ that gives finally near $8 \mathrm{~mm}$ height charge for a single portion, and then the pressing process has been repeated to fill the tube.

\subsection{Pyrotechnic heater setup}

Previously designed setup $[14,15]$ was used to study the front propagation in compacted thermite compositions. Special unit with the pyrotechnic igniter composition was used to initiate the process $[14,15]$. These experiments show the high heat release and the high pressure generated during operation inside the steel tube (up to $80 \mathrm{MPa}$ ). Therefore, in present study the tube was filled with the compacted thermite powder up to $75 \mathrm{~mm}$ of the tube length, whereas the rest of the tube was filled with compacted $\mathrm{Al}_{2} \mathrm{O}_{3}$ powder. Pressure inside the tube was tracked with the piezoelectric pressure sensor T6000 connected to a fast digital signal analyzer through the high temperature protection system (sampling frequency $5 \mathrm{kHz}$ ).

Temperature profiles were registered with a set of 15 W/Re-thermocouples (100 $\mu \mathrm{m}$ diameter of wires), which were welded onto the external surface of the tube, as shown schematically in Figure 1b. Thermocouple connection is not straightforward: with 15 thermocouple pairs simply welded on tube one faces the problem of the steel tube electrical conductivity. Binding the junction of thermocouple with glue provides the electric insulation, but this additional layer has its own thermal resistance, affecting the measured temperatures especially at high heating rates. Instead, the configuration (Figure 1c) was proposed where two wires (WR5 and WR20, where 5 or 20 number is rhenium weight percent) are welded in point 1 , and one wire WR5 is welded in point 2 . Let us define the following parameters: $T_{1}$ and $T_{2}$ are temperatures at points 1 and 2, thermo e.m.f. of pair WR5-Steel at temperature $T$ is $E_{\mathrm{WR} 5-\mathrm{St}}(T)$, the thermo e.m.f. of pair WR20-Steel at $T$ is $\mathrm{E}_{\mathrm{WR} 20-\mathrm{St}}(T)$, and $U_{1}, U_{2}$ - voltages from points 1 and 2 , respectively. Signal $U_{1}$ corresponds to thermo e.m.f. of pair WR5-WR20, with the standard dependency $T(U)$. So the temperature in point 1 is already known $\left(T_{1}\right)$. For the point 2 :

$$
\begin{aligned}
& U_{2}=E_{\mathrm{WR} 5-\mathrm{St}}\left(T_{2}\right)+E_{\mathrm{St}-\mathrm{WR} 20}\left(T_{1}\right), \\
& E_{\mathrm{WR} 5-\mathrm{St}}\left(T_{2}\right)=U_{2}+E_{\mathrm{WR} 20-\mathrm{St}}\left(T_{1}\right)
\end{aligned}
$$

Calibration procedure was performed by heating and independent external measurement of $T$ to finally get $T(U)$ dependencies for WR20-Steel and WR5-Steel pairs. Using this calibration, we obtain $E_{\mathrm{WR} 20-\mathrm{St}}\left(T_{1}\right)$, and then $\mathrm{E}_{\mathrm{WR} 5 \text {-St }}\left(T_{2}\right)$, which gives us $T_{2}$ value. This method of temperature measurement on the surface of the tube is less laborious and allows simple calculation of the "real" temperature at the certain point on the steel tube surface.

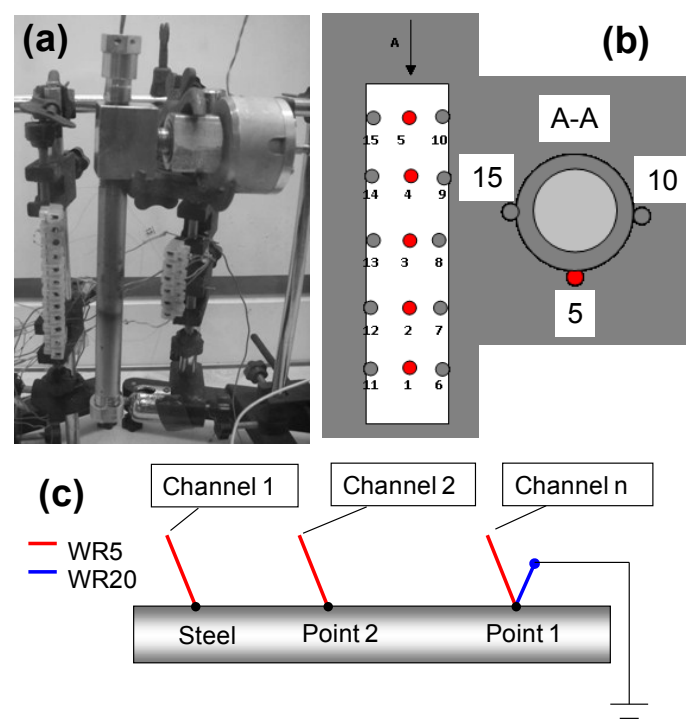

Fig. 1. Pyroheater setup (a) with the following parts: steel tube loaded with thermite, initiator, pressure sensor, and thermocouples. Sketch (b) illustrates the thermocouple contacts welded on external surface of the tube. This particular pyroheater is oriented vertically, horizontal configuration also fired. Surface discoloration on photo appeared after firing. 


\section{Results and Discussion}

\subsection{Combustion experiments within sealed tube}

The pressure generated by a micron-sized $\mathrm{Mg} / \mathrm{Fe}_{2} \mathrm{O}_{3}$ thermite combustion is shown in Figure 2 in comparison with previously studied $\mathrm{Al} / \mathrm{Fe}_{2} \mathrm{O}_{3}$ and $\mathrm{Al} / \mathrm{FeO}$ compositions $[14,15]$. Using pressure-time curves the functioning time was obtained and the overall rate has been calculated. This value for magnesium-based thermite was found to be $36 \mathrm{~mm} / \mathrm{s}$, which is slightly greater than for $\mathrm{Al} / \mathrm{FeO}$ thermite, but twice smaller than for $\mathrm{Al} / \mathrm{Fe}_{2} \mathrm{O}_{3}$ system $(65-68 \mathrm{~mm} / \mathrm{s}$ for two lots of metal powder). Detailed analysis of the pressure data, including the porosity and nanothermite effects can be found elsewhere [24].

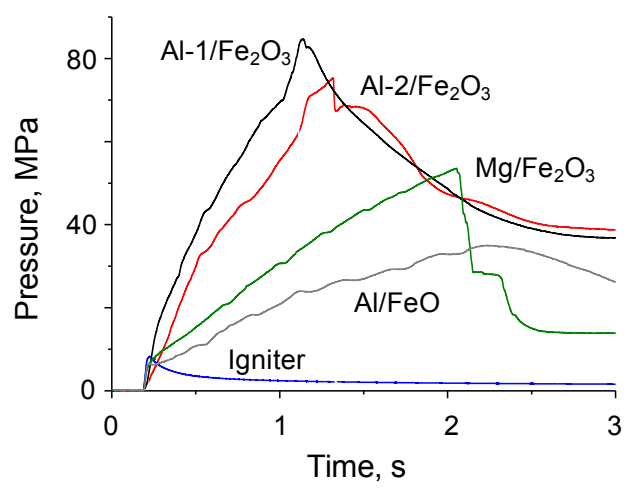

Fig. 2. Experimental pressure profiles for thermite compositions and igniter (Al-1 and Al-2 referred to aluminum powders with different particle sizes, see for details [14]).

Raw temperature data from thermocouples are presented in Figure 3. Maximal measured temperature at the external surface is $1309 \mathrm{~K}$ for $\mathrm{Mg} / \mathrm{Fe}_{2} \mathrm{O}_{3}$ composition, which exceeds values for $\mathrm{Al} / \mathrm{Fe}_{2} \mathrm{O}_{3}$ and $\mathrm{Al} / \mathrm{FeO}-1165 \mathrm{~K}$ and $1265 \mathrm{~K}$, respectively. With this temperature data in hand, the complete picture can be drawn, not only on the time base, but as a spatial function too. An example of such visualization can be found in Figure 4, fixed at the moment of attainment of the maximal temperature (denoted as " $t_{\max }$ " in Figure 3). Here, the $L$ is the longitudinal coordinate, and $A$ is the arc length of the tube surface.

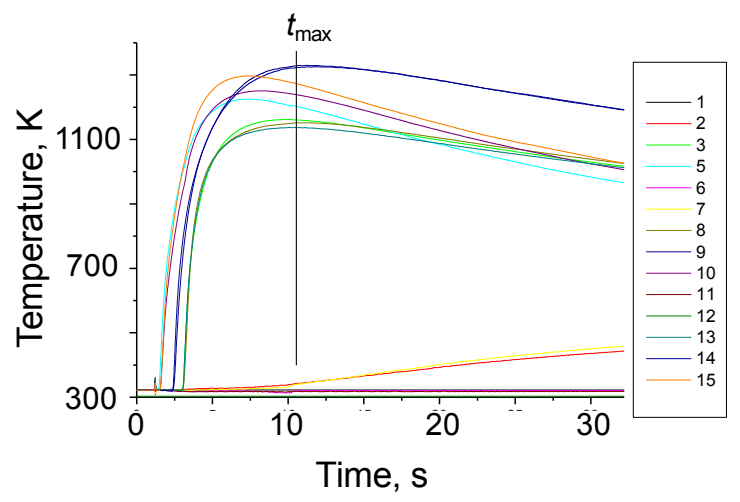

Fig. 3. Thermocouple readings, each curve corresponds to specific thermocouple (numeration according to Figure $1 b$ ). Time $t_{\max }$ corresponds to the maximal temperature attainment.

\subsection{Obtaining the combustion temperature}

Raw thermal data have been acquired by thermocouples at the outer surface of the steel tube with thermite inside. Therefore, it has to be processed to reveal the temperature-time profiles primarily produced by thermite combustion. In calculations we use temperature data for central part of the tube to exclude the heat losses near its ends. For each section the maximal temperature from three thermocouples was averaged.

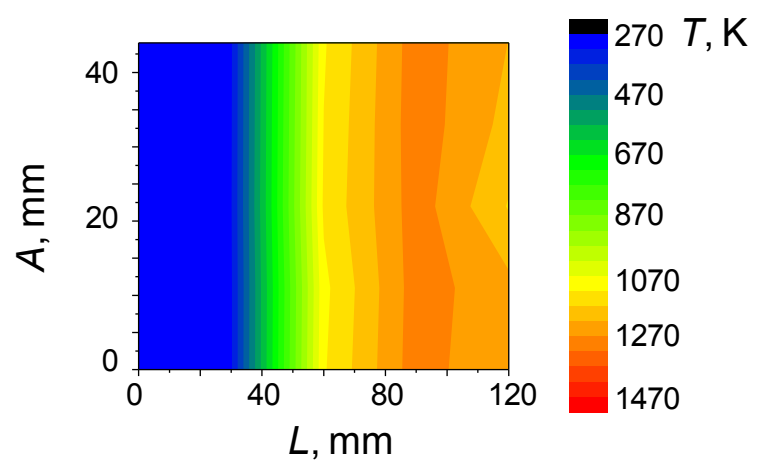

Fig. 4. Temperature map on the tube surface for the fixed time moment $t=t_{\max }$ of $\mathrm{Mg} / \mathrm{Fe}_{2} \mathrm{O}_{3}$ thermite combustion.

First, temperature at the inner surface of steel tube (casing) was calculated using thermal conductivity equation for cylindrical coordinates:

$$
\frac{d^{2} T}{d r^{2}}+\frac{1}{r} \cdot \frac{d T}{d r}=0
$$

with the boundary conditions given as:

$$
\begin{aligned}
& r=R_{1}: T=T_{s i} ; \\
& r=R_{2}:-\left.\lambda_{s} \frac{d T}{d r}\right|_{r=R_{2}}=\alpha\left(T_{s e}-T_{0}\right),
\end{aligned}
$$

where $R_{1}, R_{2}$ - inner and outer radius of the tube, $T_{\mathrm{si}}, T_{\mathrm{se}}$ - temperatures at inner and outer surfaces, $T_{0}-$ environmental temperature, $\lambda_{\mathrm{s}}$ - thermal conductivity of casing, $\alpha$ - heat transfer coefficient. Solution of Eq. (3) gives target temperature:

$$
T_{s i}=T_{s e}+\frac{\alpha R_{2}}{\lambda_{s}} \ln \left(R_{2} / R_{1}\right)\left(T_{s e}-T_{0}\right) .
$$

Taking $T_{\mathrm{se}}=1000 \mathrm{~K}, \alpha=10 \mathrm{~W} /\left(\mathrm{m}^{2} * \mathrm{~K}\right), \lambda_{\mathrm{s}}=20$ $\mathrm{W} /(\mathrm{m} * \mathrm{~K}), R_{1}=0.008 \mathrm{~m}, R_{2}=0.014 \mathrm{~m}, T_{0}=293 \mathrm{~K}$ one obtains $T_{s i}=1002.8 \mathrm{~K}$. That is, the difference between T at inner and outer surfaces is only $2.8 \mathrm{~K}$, which is less than the measurement error $(5 \mathrm{~K})$. Therefore, below we suppose $T_{\mathrm{se}}=T_{s i}$, and equal to experimental maximal temperature at the tube surface.

Heat balance equation accounting the combustion product and steel tube can be written:

$$
c_{c} m_{c}\left(T_{m}-T_{s e}\right)=c_{s} m_{s}\left(T_{s e}-T_{0}\right)
$$

where $c_{\mathrm{c}}$ and $m_{\mathrm{c}}$ are the heat capacity and mass of thermite, $c_{\mathrm{s}}$ and $m_{\mathrm{s}}-$ that values for the casing. Equation (5) was used without convective and radiation heat losses, its accounting results only in marginal difference in maximal temperature, $<10 \mathrm{~K}$, and thus was 
eliminated. Combustion products temperature is expressed now as:

$$
T_{m}=T_{s e}+\frac{c_{s} \rho_{s}}{c_{c} \rho_{c}}\left(T_{s e}-T_{0}\right)\left(\left(\frac{R_{2}}{R_{1}}\right)^{2}-1\right),
$$

where $\rho_{\mathrm{s}}$ and $\rho_{\mathrm{c}}$ are the densities for tube and thermite respectively. For tube material $c_{\mathrm{s}}=500 \mathrm{~J} /\left(\mathrm{kg}^{*} \mathrm{~K}\right), \rho_{\mathrm{s}}=$ $7900 \mathrm{~kg} / \mathrm{m}^{3}$, the heat capacity value for thermite reaction products was calculated with data from [25], $c_{\mathrm{c}}=1265$ $\mathrm{J} /\left(\mathrm{kg}^{*} \mathrm{~K}\right)$. Average density of the products remains the same as for initial mixture, since the system is closed.

Figure 5 represents the calculated combustion temperature against an average porosity of thermite charge, showing no influence of the latter. Resulting values for $\mathrm{Mg} / \mathrm{Fe}_{2} \mathrm{O}_{3}$ thermite fall within 3140-3280 K range. Processing of the previous data acquired for pyroheaters [14] in the same way, we get the results for initiation at the environmental temperature below $273 \mathrm{~K}$ and for horizontal position of the tube (both relevant to space applications). Lowering the environmental temperature down to $213 \mathrm{~K}$ slightly reduces the combustion products temperature. Tube orientation (vertical or horizontal) shows no influence on temperature, imposing that melt flow is not the governing the process. Nanothermites reveal the combustion temperature in $500 \mathrm{~K}$ lower than for micronsized system. A plausible explanation is the decrease in metal content for nano-Mg (not determined).

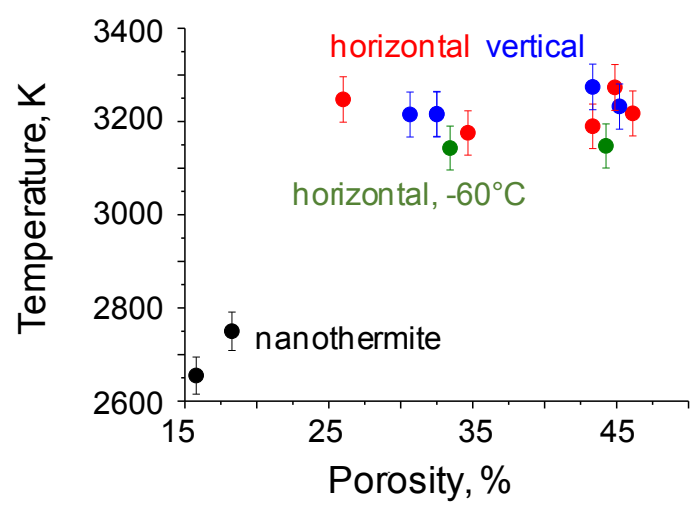

Fig. 5. Temperature of the combustion products computed with Eq. (6) versus porosity of thermite charge.

\subsection{Thermodynamic calculation of thermite combustion}

Thermodynamic parameters for the combustion products have been calculated using THERM software [26]. Two problems were considered - combustion at constant pressure (HP) and constant volume (UV). Adiabatic combustion temperature values obtained are $3031 \mathrm{~K}$ (0.1 MPa), 3186 (1 MPa), 3183 (10 MPa). For constant volume problem (charging density of $0.468 \mathrm{l} / \mathrm{kg}$ ) the computed composition of products reveal almost only condensed species $(Z=0.99)$, consequently small pressure buildup revealed $(0.09 \mathrm{MPa})$. The adiabatic temperature in this case was found to be $3161 \mathrm{~K}$. Analysis of the characteristic temperatures for condensed species involved reveals that at $3160-3180 \mathrm{~K}$ reactant $\mathrm{Mg}$ is boiled, iron oxide is decomposed, possible product $\mathrm{Fe}$ is in liquid and gas phases, and $\mathrm{MgO}$ is just melted (Figure 6).

Table 1 lists the equilibrium composition of gaseous and condensed products. With pressure increase fewer species are predicted with the dominant $\mathrm{Fe}(\mathrm{l})$ and $\mathrm{MgO}$ (1). For constant volume calculations the composition is in between that for atmospheric pressure and $1 \mathrm{MPa}$, in agreement with small, but noticeable pressure buildup predicted.

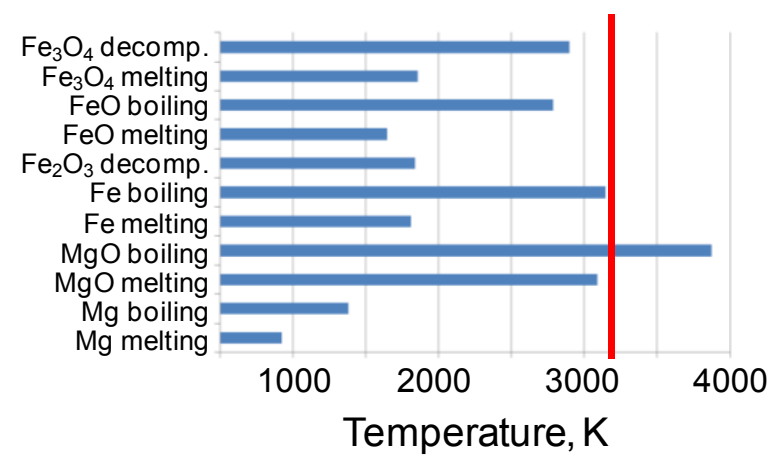

Fig. 6. Characteristic temperatures for involved species from [27]. Computed adiabatic temperature is shown as red line.

Table 1. Composition of combustion products revealed by thermodynamic calculations.

\begin{tabular}{|c|c|c|c|c|}
\hline \multirow{2}{*}{ Product $^{\text {a }}$} & \multicolumn{3}{|c|}{ HP-problem } & \multirow{2}{*}{$\begin{array}{c}\text { UV- } \\
\text { problem }\end{array}$} \\
\cline { 2 - 4 } & $0.1 \mathrm{MPa}$ & $1.0 \mathrm{MPa}$ & $10 \mathrm{MPa}$ & $2.7 \mathrm{E}-3$ \\
\hline $\mathrm{Mg}$ & 2.29 & $4.6 \mathrm{E}-3$ & $3.6 \mathrm{E}-7$ & $2.8 \mathrm{E}-5$ \\
\hline $\mathrm{O}$ & 0.021 & & & 0.011 \\
\hline $\mathrm{Fe}$ & 10.9 & $3.3 \mathrm{E}-3$ & $1.5 \mathrm{E}-6$ & $1.5 \mathrm{E}-5$ \\
\hline $\mathrm{O}_{2}$ & 0.012 & & & $4.4 \mathrm{E}-4$ \\
\hline $\mathrm{FeO}$ & 0.36 & $2.3 \mathrm{E}-5$ & & \\
\hline $\mathrm{FeO}_{2}$ & 0.001 & & & \\
\hline $\mathrm{Mg}_{2}$ & $7.3 \mathrm{E}-5$ & & & $5.7 \mathrm{E}-4$ \\
\hline $\mathrm{MgO}^{2}$ & 0.38 & $1.7 \mathrm{E}-4$ & & 47.7 \\
\hline $\mathrm{Fe}^{*}$ & 32.0 & 48.0 & 47.9 & 1.5 \\
\hline $\mathrm{FeO}^{*}$ & 6.2 & & 0.2 & 51.4 \\
\hline $\mathrm{MgO}^{*}$ & 47.8 & 52.0 & 51.9 & \\
\hline
\end{tabular}

${ }^{\mathrm{a}}$ Asterisk marks the condensed materials.

\subsection{Comparison of theoretical calculations with experiment}

Condensed products after thermite combustion were analyzed to reveal some insight into the process mechanism. They represent the solid porous cylinder with clear interfaces between thermite loadings (Figure 7). Electron microscopy of this framework reveals the non-homogeneous structure, while the energy-dispersive analysis was used to determine the elemental composition in regions of interest. Main 
species obtained include $\mathrm{Fe}, \mathrm{Fe}_{2} \mathrm{O}_{3}, \mathrm{MgO}$ and spinel $\mathrm{MgFe}_{2} \mathrm{O}_{4}$. Metal iron appears as large droplets, confined in the matrix of $\mathrm{Mg}$-containing components (Figure 7). Comparison of the identified products with the composition predicted theoretically (Table 1) reveals nice agreement with an exception of the spinel substance. It is not included in thermodynamic database of applied software, and probably neglecting this product causes the adiabatic temperature to be slightly smaller than actually measured. Recently, the same effect was shown for $\mathrm{Al} / \mathrm{CuO}$ thermite, where accounting of binary $\mathrm{Al}-\mathrm{Cu}$ and ternary $\mathrm{Al}-\mathrm{Cu}-\mathrm{O}$ phases refines the computed temperatures [28]. Near stoichiometry the refinement, i.e., difference between thermodynamic calculation with reduced set of products ("pure substance approach") and that with full set (including e.g., $\mathrm{Al}_{2} \mathrm{CuO}_{4}$ ) is up to 150 degrees. Incompleteness of the reaction can be another factor causing the discrepancy between computation and experiment.

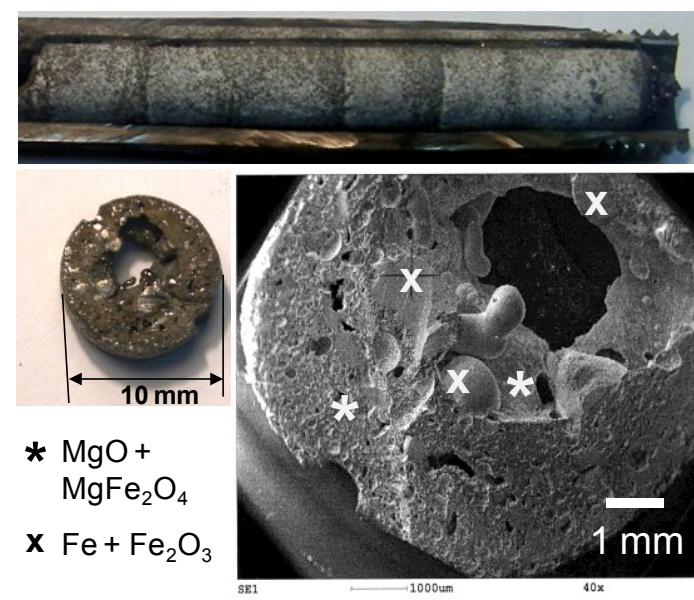

Fig. 7. Solid framework revealed after thermite combustion: optical and electron microscopy images along with the results of the elemental analysis.

\section{Conclusions}

Combustion-wave propagation of thermite reactions $\mathrm{Mg} / \mathrm{Fe}_{2} \mathrm{O}_{3}$ has been investigated in pyrotechnic heater setup, i.e., inside the sealed steel tube, under elevated pressure, which is generated by the evaporation and heat expansion of involved species. Temperature distribution along the steel tube was obtained experimentally for thermite with micron- and nanosized components. The combustion products temperature was calculated using raw experimental data (temperature at the external surface of the sealed tube). No obvious dependency of calculated temperature on porosity has been found. Decrease of the initial surrounding temperature from $298 \mathrm{~K}$ to $213 \mathrm{~K}$ and the use of nanothermite $\mathrm{Mg} / \mathrm{Fe}_{2} \mathrm{O}_{3}$ result in the combustion product temperature reduction. Obtained in thermodynamic calculations the adiabatic temperatures are close to the experimental ones, but in $3 \%$ less, possibly because of neglecting of spinel-type products in computations.

Thus, the pyroheater setup appears to be useful in deriving the temperature data for thermite reaction, which are important for clarification of the mechanism of thermite reaction. In general, proposed technique allows reconstruction of the temperature data during reactive materials combustion with a certain spatial and temporal resolution, even for harsh and high-temperature environment of thermite reaction, where some other methods fall to track the whole heating process.

Authors acknowledge FASO of Russian Federation (project 0082-2018-0002, registration code AAAA-A18118031490034-6) for a financial support of this work.

\section{References}

1. L.L. Wang, Z.A. Munir, Y.M. Maximov, J. Mater. Sci. 28, 3693-3708 (1993)

2. Y. Goldschmidt, Iron Age. 82, 232 (1908)

3. S. Valliappan, J. Swiatkiewicz, J.A. Puszynski, Powder Technol. 156, 164 (2005)

4. J.A. Puszynski, C.J. Bulian, J.J. Swiatkiewicz, MRS Proc. 896 (2005)

5. D. Spitzer, M. Comet, C. Baras, V. Pichot, N. Piazzon, J. Phys. Chem. Solids. 71, 100 (2010)

6. M. Pantoya, J. Granier, Propellants Explos. Pyrotech. 30, 53 (2005) 53-62

7. S.H. Fischer, M.C. Grubelich, Proc. 24th Int. Pyrotechnic Seminar, 231 (1998)

8. M.S. Ding, F.C. Krieger, J.A. Swank, Army Research Laboratory Technical Report ARL-TR6664 (2013)

9. A.J. Swiston, T.C. Hufnagel, T.P. Weihs, Scr. Mater. 48, 1575 (2003)

10. S.J. Apperson, A.V. Bezmelnitsyn, R. Thiruvengadathan, K. Gangopadhyay, S. Gangopadhyay, W.A. Balas, P.E. Anderson, S.M. Nicolich, J. Propuls. Power. 25, 1086 (2009)

11. I. Puchades, M. Hobosyan, L.F. Fuller, F. Liu, S. Thakur, K.S. Martirosyan, S.E. Lyshevski, 14th IEEE Int. Conference on Nanotechnology, 83 (2014)

12. C.E. Johnson, K.T. Higa, MRS Proc. 1521 (2013)

13. C. He, J. Zhang, J.M. Shreeve, Chem. - Eur. J. 19, 7503 (2013)

14. Y. Frolov, A. Pivkina, D. Ivanov, D. Meerov, K. Monogarov, N. Murav'ev, D. Dilhan, S. Mudretzova, Theory and Practice of Energetic Materials 7, 301 (2007)

15. K. Monogarov, A.N. Pivkina, Y.V. Frolov, N. Muravyev, O.S. Ordzhonikidze, Proc. 36th Int. Pyrotechnic Seminar 307 (2009)

16. S. Goroshin, A.J. Higgins, L. Jiang, K. MacKay, P.V. Ashrit, Sci. Technol. 16, 322 (2005)

17. K.A. Monogarov, A.N. Pivkina, L.I. Grishin, Y.V. Frolov, D. Dilhan, Acta Astronaut. 135, 69 (2017)

18. K. Monogarov, V. Trushlyakov, K. Zharikov, M. Dron, Y. Iordan, D. Davydovich, I. Melnikov, A. Pivkina, Acta Astronaut. DOI:10.1016/j.actaastro.2017.11.028 
19. B.S. Bockmon, M.L. Pantoya, S.F. Son, B.W. Asay, J.T. Mang, J. Appl. Phys. 98, 064903 (2005)

20. K. Sullivan, M. Zachariah, J. Propuls. Power. 26, 467 (2010)

21. M. Schoenitz, T.S. Ward, E.L. Dreizin, Proc. Combust. Inst. 30, 2071 (2005)

22. V.I. Levitas, M.L. Pantoya, S. Dean, Combust. Flame. 161, 1668 (2014)

23. M.L. Pantoya, V.I. Levitas, J.J. Granier, J.B. Henderson, J. Propuls. Power. 25, 465 (2009)

24. K. Monogarov, A. Pivkina, N. Muravyev, D. Meerov, D. Dilhan, Phys. Procedia. 72, 362 (2015)

25. NIST Chemistry WebBook, available at: http://webbook.nist.gov

26. THERM: Method and software for calculation of the equlibrium composition and parameters of combustion products for multicomponent systems, JSC "FSPC"Institute of Applied Chemistry", (Sergiev Posad, Russia, 1985)

27. I.S. Grigoriev Physical Values Handbook (Energoatomizdat, Moscow, 1991)

28. K. Hack, Introducing the Integrated Thermodynamic Databank System FactSage Presentation at 14th Workshop on Pyrotechnic Combustion Mechanisms (2018) 